\title{
OS PAPÉIS DA DISCIPLINA DE PAISAGISMO: UMA DISCUSSÃO A RESPEITO DO UNIVERSO NECESSÁRIO PARA PROMOVER UM AVANÇO À INSERÇÃO DA DISCIPLINA DE PAISAGISMO NO CURSO DE ARQUITETURA E URBANISMO
}

\author{
SILVA, Jonathas Magalhães Pereira da \\ Arquiteto, Doutor pela Faculdade de Arquitetura e Urbanismo da Universidade de São Paulo, Professor de \\ Paisagismo no Grupo de Projeto da Faculdade de Arquitetura Anhembi Morumbi. \\ E-mail: jonathas@mpsassociados.com.br
}

\section{RESUMO}

O presente artigo é fruto da pesquisa de doutoramento desenvolvida na FAUUSP sob orientação de Silvio Soares Macedo e procura avançar em algumas reflexões a partir da argüição da banca composta por: Ana Gabriela Godinho Lima, Euler Sandeville, Miranda M. Magnoli e Nidia Nacib Pontuschka.

A tese defendida se intitula "O Papel da Disciplina de Paisagismo na Formação de Arquitetos Urbanistas". O próprio título do presente artigo é fruto de uma provocação de Euler Sandeville quando propõe em pluralizar o título original da tese, potencializando um pensamento mais abrangente, mais complexo e certamente mais completo a respeito da disciplina.

O leitor não irá encontrar respostas às questões colocadas, entretanto será convidado a refletir a respeito dos conteúdos e abrangências da disciplina de paisagismo assim como será incentivado a buscar uma identidade ao universo aqui apresentado. Espera-se poder contribuir na promoção de uma construção conjunta a respeito da disciplina e de seus papeis.

A tese de doutorado desenvolvida promove a discussão sobre a qualidade da formação do arquiteto urbanista na medida em que explicita a ética desejada e revê as responsabilidades, conteúdos e procedimentos da disciplina de Paisagismo, colocando em questionamento a efetiva contribuição das disciplinas de Paisagismo nos cursos de Arquitetura e Urbanismo.

A hipótese colocada é que a disciplina de Paisagismo colabora para que o aluno tome para si os compromissos éticos inerentes às questões relacionadas à ocupação do território, ao uso dos recursos ambientais e do espaço público, nas mais variadas escalas. Tal apropriação é condição essencial para que o arquiteto urbanista possa assumir, de forma responsável, todas as suas atribuições profissionais, estabelecidas pela legislação brasileira.

\section{Palavras-chave: Paisagem, ensino, método.}

\begin{abstract}
This paper is the result of the doctorate research thesis developed by the author in the School of Architecture and Urbanism of the University of São Paulo-FAUUSP, under the advisory of Prof. Silvio Soares Macedo. It aims to deep some discussions held during the oral examination by the professors Ana Gabriela Godinho Lima, Euler Sandeville, Miranda M. Magnoli and Nidia Nacib Pontuschka.

The thesis focused here is called "The role of Landscape Discipline in the Education of Architects and Urbanists". The title of this article itself is a result of the comments made by Prof. Euler Sandeville when he suggested to enhance the original thesis title, providing a more comprehensive, complex and complete idea about the landscape discipline.

The reader will not found the answers to the questions posed, however he or she will be invited to reflect about the landscape discipline concepts and contempts and will be motivared to search for an identity to the universe presented here. We expect to promote a collective construction about the discipline and its roles. The thesis itself opens up the discussion about the architect and urbanist education quality, by explaining the desired ethic, by reviewing the responsabilities, the contempts and proceedings of the Landscape Design courses and by questioning their effective contribution to the Architecture and Urbanism schools in Brazil.
\end{abstract}


The hypothesis being demonstrated is that the Landscape Architecture disciplines are important to the profession because they enable the architect and urbanist to undertake the legal competences, established by Brazilian legislation, and allows this professional to assume the ethical commitments with the questions and problems related to the territory occupation issues, dealing with environmental resources and public spaces, in the most variable scales.

\section{Key words: Landscape, teaching, methods.}

\section{Introdução}

Identifica-se que, após doze anos de obrigatoriedade da disciplina de paisagismo em escolas de arquitetura e urbanismo, essa disciplina ainda necessita posicionar-se perante o curso.

Se, em algumas escolas, o ato de conferir visibilidade à importância da disciplina de Paisagismo deveria dar-se de forma mais explícita, em outras, o posicionamento da disciplina perante o curso deveria sofrer uma radical transformação afastando-se do reducionismo a que o tema estava submetido e suas implicações na formação dos arquitetos urbanistas.

Antes de elaborar formas de transformar os cursos de arquitetura e urbanismo públicos e privados com suas diferentes realidades e amarras administrativas, políticas e ideológicas deve-se refletir na real pertinência da disciplina de Paisagismo na formação de arquitetos urbanistas.

Se considerarmos a paisagem como reflexo das ações da sociedade sobre o território, pode-se discutir os processos de alteração desta paisagem por meio de ações diretas e por meio de projetos e planos, a fim de atender o querer momentâneo da sociedade; ou pode-se intervir indiretamente na paisagem questionando e ampliando o querer desta mesma sociedade por meio da educação.

Se a paisagem é transformada pela sociedade pode-se pensar em modificar a paisagem agindo sobre os valores desta sociedade. Certamente será a atuação mais ampla e efetiva na paisagem, independentemente do fator tempo, inerente à transformação social.

Ao tratarmos da questão do ensino de paisagismo, seguimos esta via onde se acredita que os arquitetos urbanistas brasileiros devam ter um importante papel social ao questionar e intervir sobre as desigualdades sociais e os processos de exclusão presentes na realidade nacional, por meio da leitura e de ações tomadas sobre a paisagem ora pelo Estado ora pela população.

Cabe ao arquiteto urbanista conhecer os processos históricos, sócio-culturais e econômicos que transformaram o território. A disciplina de Paisagismo tem um papel relevante na formação deste ator social que trabalha com a paisagem, concebendo um projeto de edifício, um jardim, um conjunto habitacional, uma intervenção urbana, um parque, um sistema de transporte, ou o planejamento de uma cidade ou região.

O arquiteto urbanista do início do século XXI não pode se ater a uma formação técnica e competente que apenas vise a atender à demanda do mercado de trabalho, fato que historicamente modelou o ensino superior no Brasil. É necessário avançar, ir além, fazer do ensino um meio para a formação de arquitetos urbanistas que saibam responder às necessidades da sociedade como agentes da transformação social e, portanto, ser um dos condutores da transformação da paisagem.

Para isso há a necessidade de consolidar o processo, já iniciado na década de 50, quando a disciplina de Paisagismo já não se limitava a projetos de jardins e, desde aquela época, iniciava 336 um longo processo de crescimento de seu escopo por meio da reflexão da função social dos espaços livres de edificação e das relações das atividades humanas com o ambiente.

No início do século XXI, as realidades são diversas no campo da educação, estando à mostra vários pontos frágeis a começar pelas posturas éticas e ideológicas antagônicas de seus 
responsáveis, pela vocação, nem sempre revelada, das Instituições Superiores de Ensino, que defendem interesses diversos, pelo engessamento das estruturas institucionais, e, até mesmo, pelo insípido mercado de trabalho existente para arquitetos urbanistas.

Se por um lado este cenário remete a tempos sombrios, por outro, indica estarmos perto de um colapso do sistema de ensino superior vigente, em especial ao de arquitetura e urbanismo. Vive-se em uma crise generalizada do ensino superior junto a uma crise específica do ensino de arquitetura e urbanismo, sendo este um momento propicio para rever o papel social do arquiteto urbanista brasileiro.

É necessário extrair, de nossa realidade local, as propostas para a condução da educação da sociedade brasileira, que vem se modificando rapidamente, nos últimos vinte e cinco anos, a forma de ocupação do território e transformando assim a paisagem e o meio ambiente.

\section{Regulamentação e qualificação do ensino}

Um produto ideológico faz parte de uma realidade (natural ou social) como todo corpo físico, instrumento de produção ou produto de consumo; mas, ao contrário destes, ele também reflete e refrata uma outra realidade que lhe é exterior.

Mikhail Bakhtin

As disciplinas acadêmicas podem ser vistas como "produtos ideológicos" onde se "reflete e refrata" a realidade de uma sociedade. Nesse sentido, o surgimento de uma disciplina não se impõe a uma realidade, mas é fruto do entendimento dela. Ao pesquisar o objeto, busca-se o conhecimento de uma realidade exterior. $O$ entendimento desse objeto é fruto de várias etapas do conhecimento que são garimpadas das discussões sobre o produto ideológico pretendido.

A história da disciplina de Paisagismo no Brasil vem se desenvolvendo desde o início dos anos 1950. As discussões sobre as transformações ocorridas no mundo nos últimos cinqüenta anos do século XX, no âmbito das questões sociais e ambientais, promovem uma revisão do ensino do paisagismo quanto ao correto entendimento de seu objeto e a necessidade do desenvolvimento de uma abordagem que atenda as demandas da sociedade.

Fruto desses questionamentos é criado, em 1993, um fórum de discussão sobre a disciplina: seu objeto e seus métodos. Esse fórum acontece em São Paulo, na FAUUSP, e é denominado Colóquio sobre Ensino de Arquitetura Paisagística no Brasil. Foi este encontro que deu origem ao ENEPEA-Encontro Nacional de Ensino de Paisagismo em Escolas de Arquitetura e Urbanismo no Brasil. Tais seminários de porte nacional são realizados, em um primeiro momento, anualmente e, a partir do terceiro encontro, passam-se a adotar encontros bienais, como forma ideal.

Por ocasião do I ENEPEA, realizado em outubro de 1994, fez-se um grande esforço para mapear e discutir a disciplina de Paisagismo nos cursos de Arquitetura e Urbanismo. Desse trabalho resultou um quadro que conferia uma maior visibilidade sobre as condições do ensino de Paisagismo em diferentes instituições de ensino naquele ano.

O quadro tratava de explicitar a situação da disciplina de Paisagismo nos cursos de Arquitetura e Urbanismo, até então não regulamentada nem tida como disciplina obrigatória, caracterizando cada IES - Instituição de Ensino Superior - presente no encontro por meio do: tempo de existência da instituição, da natureza pública ou privada, da ocorrência ou não de cursos de pós-graduação e da inserção curricular da disciplina de Paisagismo, detalhando sua periodicidade, conteúdos e procedimentos didáticos e, por fim, explicitando a que departamento do curso estava ligada a disciplina Paisagismo. 


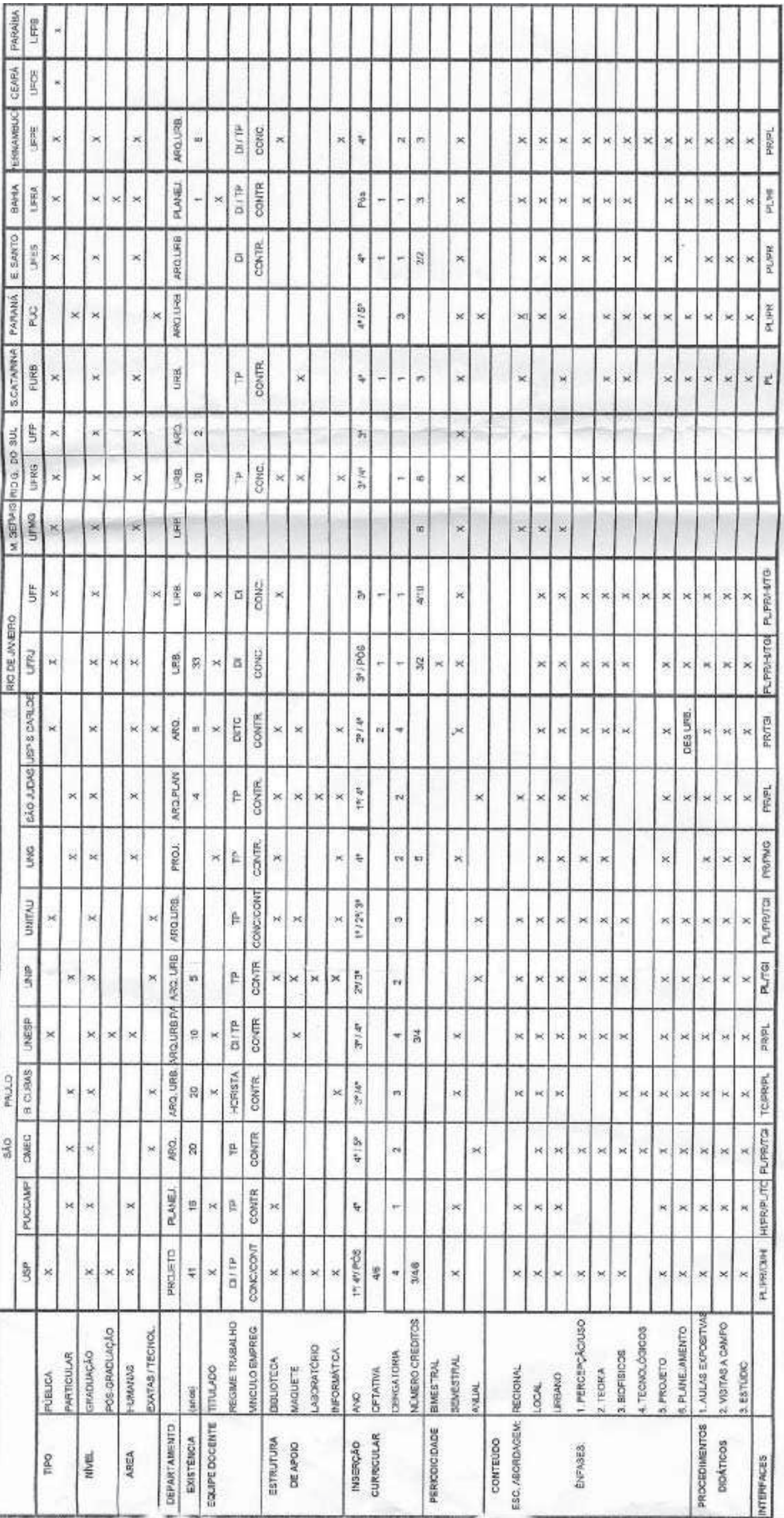


Foram 22 instituições analisadas na época, sendo dez estabelecidas no estado de São Paulo, duas no Rio de Janeiro, outras duas no Rio Grande do Sul e as oito restantes nos estados de Minas Gerais, Santa Catarina, Paraná, Espírito Santo, Bahia, Pernambuco, Ceará e Paraíba. Segundo a ABEA - Associação Brasileira de Escolas de Arquitetura - em 1994 existiam 74 cursos de Arquitetura e Urbanismo no país.

Passados mais de 10 anos do primeiro encontro, muita coisa se alterou no mundo, no país e nas nossas escolas de Arquitetura e Urbanismo. O número de IES que possuem o curso de Arquitetura e Urbanismo no país aumentou e hoje, segundo a ABEA, existem 183 cursos regulamentados. Isso demonstra, em um primeiro momento, uma demanda real pelo profissional, derivada diretamente do processo contínuo e intenso da urbanização nacional na década de 1990.

Associada a essas demandas está a busca pelo profissional dedicado ao campo do conhecimento em Paisagismo, cuja solicitação aumenta na medida em que extensas áreas são urbanizadas, as solicitações sociais por espaços de recreação, tanto públicos como privados, crescem em progressão geométrica e as questões ambientais e paisagísticas na ocupação do território são objeto de estudo e regulamentação, tanto pelo Estado como pela sociedade civil.

Por outro lado, no campo do ensino universitário, a introdução de novos métodos de ensino, especialmente aqueles ligados ao campo da informática, são realidade, e a internet se torna um veículo de comunicação entre os diferentes extratos da sociedade e desta com a universidade.

\section{Aa diferentes escalas de abordar o objeto de estudo}

Essas posturas perante a sociedade e a paisagem levam a uma série de preocupações básicas, quando se trata da formulação de um projeto pedagógico para a disciplina de Paisagismo. Os professores do GDPA - Grupo de Disciplina de Paisagem e Ambiente da FAUUSP - , em artigo publicado nos ANAIS do referido encontro, colocam as preocupações quanto ao enfoque da disciplina (1996):

Os cursos acadêmicos de Paisagismo devem fornecer os instrumentos conceituais e técnicos necessários para operar nos diversos setores e nas várias escalas de intervenção na paisagem. No ensino de Paisagismo, aprofundar técnicas e procedimentos de levantamento, de análise, de avaliação e de representação gráfica, propor enfoques e métodos adequados para o projeto, planejamento e requalificação da paisagem, valorizar características físicas do lugar entendendo as transformações e o encadeamento de eventos que caracterizam sua dinâmica, avaliar sua capacidade para colher atividades, mudanças e usos particulares, são exigências curriculares essenciais, que revelam o grau de adequação da estrutura científica e didática nas respostas às diferentes necessidades de projeto da paisagem e, suas escalas de entendimento e intervenção, e que permite enfrentar as complexas e emergentes instâncias que resultam da realidade territorial do país. (p. 63)

Aqui estão reveladas as preocupações com um aprimoramento dos métodos e procedimentos, assim como a necessidade de um grau de abrangência nas diversas escalas por parte da disciplina. A referida exigência quanto ao trabalho com as diferentes escalas, embora esteja contemplada na regulamentação da disciplina pelo MEC, tem uma grande dificuldade de entendimento. Contudo a colocação, durante a palestra do II ENEPEA proferida pela então professora Titular da FAUUSP Dra Miranda Magnoli, de que "escala de atuação não se confunde com escala de compreensão" é uma diretriz clara de que as escalas devem ser compreendidas simultaneamente, independente da escala do exercício proposto. 
Existe uma confusão, comum nos cursos de Arquitetura e Urbanismo, entre tema de exercício e conteúdo pedagógico. Independente da escala, do tema de estudo adotado, sem uma visão das demais escalas não é possível promover por meio da prática pedagógica o entendimento da paisagem como sistema nem da morfologia, isto é, da identificação dos fenômenos que implicados na constituição de sua forma (LAMAS, 1996).

\section{Universo do ensino do paisagismo}

Na construção do universo de abrangência, proposto para o ensino de Paisagismo nas escolas de arquitetura e urbanismo no Brasil, partiu-se de alguns pressupostos que passam aqui a serem declarados e, na medida do possível, justificados.

O primeiro pressuposto é de que o foco, no estudo da paisagem, está em entender e promover a sua transformação. Isto é, levam-se em conta os recursos naturais e as sociedades humanas, buscando-se, portanto, uma paisagem onde os recursos naturais e as diferenças sociais sejam consideradas no processo de planejamento e construção da realidade.

Toma-se por ldeal o campo das idéias onde residem os conceitos, as culturas e os pensamentos de que levam as Nações a se organizarem de uma determinada maneira sobre o Território.

É necessário deixar claro o sentido do "ideal" aqui utilizado. $\bigcirc$ "ideal" é fruto de operações racionais do entendimento assim como colocado por Henri Lefebvre. Portanto, aos referirmos ao conceito de "ideal" não se está lidando com o "idealismo", tão criticado por Friedrich Nietzsche, segundo qual, o "idealismo" teria, como característica, a construção de falsas verdades promovendo a fuga da realidade.

Parte-se do "ideal" como fruto de uma construção social desprovida de preconceitos, portanto, segundo Mikhail Bakhtin, com possibilidades de desenvolver o conhecimento ${ }^{2}$. Dessa forma, o ideal aqui colocado tem como objetivo desvendar a realidade e não contribuir para o seu mascaramento.

Por outro lado, tomam-se por Real as regras e pactos estabelecidos pelas sociedades na organização dos elementos que constituem a paisagem. A realidade aqui trabalhada é construída pela experimentação.

É também necessário explicitar o valor do termo "sociedade", utilizado, no presente artigo. Temse o conceito de "sociedade" como sendo fruto de um pensamento ideal, isto é, construído por operações racionais. Portanto as sociedades não existem fora da mentes que as construíram.

Entretanto confere-se uma concretude à abstrata "sociedade" quando afloram, dela mesma, os grupos sociais que a constituem. É oportuno lembrar que, por sua vez, esses grupos sociais são formados por indivíduos que tem interesses e objetivos comuns.

A transformação da Paisagem que nos interessa, nesta discussão, é aquela proveniente da interação desse trinômio - sociedade, grupos e indivíduos - com o território.

Conforme declarado, o universo aqui proposto para o ensino da disciplina de paisagismo navega portanto entre o Real e o ldeal, por meio da formação do indivíduo. Essa formação do sujeito pressupõe uma investigação de novos valores e, portanto, de um questionamento das ações (procedimentos) estabelecidas pela sociedade.

Portanto, pretende-se destacar o ensino que promove a construção do conhecimento ao mes340 mo tempo em que leva a uma aproximação com a realidade potencializando, dessa forma, a capacidade de transformação da realidade, investigando e questionando os valores presentes na sociedade.

Lidamos com atributos ideais quando investigamos os valores presentes em uma sociedade. 
Essas investigações levam à formulação de conceitos e promove o estabelecimento de diretrizes de transformação da paisagem. Do mesmo modo, o questionamento da realidade, por meio da Leitura de seus objetos, possibilita a investigação de valores sociais.

Desta forma, o planejamento da paisagem necessita de uma ética comum para possibilitar a criação das regras (termo de referência) que possibilite estabelecer diretrizes com a finalidade de promover projetos adequados e circunstanciados por normas pré-definidas pela sociedade.

Tendo em vista a sociedade e seu contexto, a partir da Leitura da Realidade, são necessárias ações individuais, coletivas e sociais de forma a alterar o estado de valores de sua população. Nesse sentido não existe Lei legítima sem cidadania da mesma forma que não existe projeto adequado sem planejamento

O estabelecimento de pactos sociais qualifica e transforma a legislação. Esses pactos só se tornam possíveis por meio da conquista do direito em participar, como cidadão, do planejamento da paisagem, definindo dessa forma, as ações e valores prioritários.

Dessa forma o universo aqui apresentado navega entre a concretude da realidade a subjetividade de um querer ideal ${ }^{3}$.

O resultado é um quadro sintético que pressupõe, na sua constituição, uma concepção de ensino e de paisagem. Partindo do conceito de síntese (operação racional por excelência) e análise (operação da inteligência), Lefebvre aponta ${ }^{4}$ :

"Quer essas operações sejam experimentais (reais) ou racionais (ideais), são inseparavelmente ligadas; pode-se dizer que existe apenas, no curso do trabalho do conhecimento que penetra no concreto, uma acentuação colocada ora sobre a diferença (mediante a análise), ora sobre a unidade (mediante a síntese)".

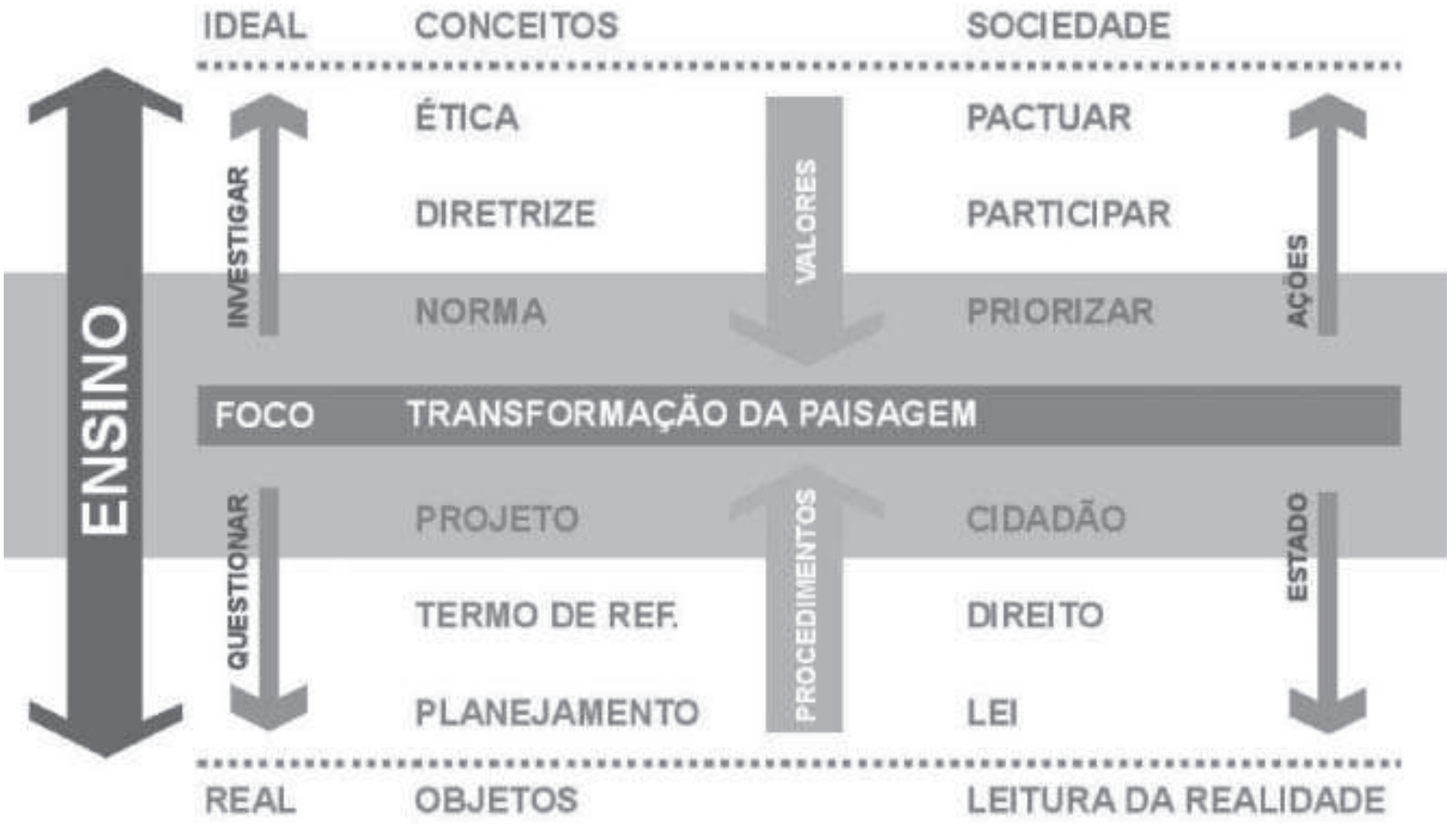

\section{Conclusão}

Baseados nos princípios aqui apresentados pode-se modelar diferentes ações concretas a serem tomadas em sala de aula. Um exemplo disso é a já antiga discussão a respeito da necessidade de estudar as diversas escalas de atuação na paisagem simultaneamente. 
Tomando esse exemplo podemos observar, segundo levantamento efetuado para a pesquisa de doutorado, um número representativo de docentes que excluem a escala regional do escopo da disciplina por diferentes razões, alguns pelo tempo escasso, outros por falta de referência quanto à prática pedagógica, dentre outras ${ }^{\mathrm{e}}$.

Entretanto, a escala regional, por meio do planejamento da paisagem, possibilita, a seu pesquisador, questionar valores e explicitar os consensos e dissensos contidos nas ações tomadas pela sociedade sobre a paisagem; permitindo desta forma uma formação mais completa e ciente das realidades físicas e sócio-culturais existentes.

Outro ponto, que se revela igualmente importante, é a necessidade de conduzir a concepção dos espaços, finalidade primeira do arquiteto urbanista, de forma consciente de modo a questionar as hierarquias de valores dominantes a favor da paisagem, do meio ambiente e da transformação da sociedade desigual em que estamos inseridos.

A consciência da realidade física e sócio-cultural é fundamental para que o arquiteto urbanista conceba os espaços - tendo como objeto desde um edifício ou um jardim até um macrozoneamento regional ou um plano de manejo de um parque - que respondam e explicitem o QUERER da sociedade.

Nesse sentido, o futuro profissional deveria sair do curso de arquitetura e urbanismo curioso por entender seu papel, desprovido de estilos próprios e de idéias pré-concebidas. A curiosidade profissional, embasada por pesquisas específicas, deveria ser a bússola orientadora para o profissional que tem por tradição aprender no decorrer da ação, aprender fazendo.

Resta, portanto, questionar quais seriam as habilidades e competências profissionais que deveriam ser identificadas e desenvolvidas ao longo do curso de graduação pela disciplina de Paisagismo em sintonia com as demais disciplinas do curso. Sugiro que algumas sejam pesquisadas e discutidas com mais profundidade, tais como:

- Desenvolver a capacidade de percepção das dimensões e escalas adequadas para as diferentes atividades e necessidades humanas.

- Desenvolver a capacidade de promover a visibilidade dos processos de apropriação dos recursos naturais no decorrer de uma ocupação espacial do território, por meio de instrumentos específicos de representação.

- Desenvolver a capacidade de conduzir propostas de intervenção na paisagem que lidem com diferentes áreas do conhecimento e/ou com expectativas contraditórias dos diferentes agentes envolvidos.

- Identificar as habilidades, de expressão artística, necessárias para a inclusão de um maior número de pessoas historicamente excluídas da condução do processo de transformação da paisagem.

- Identificar as habilidades, de relacionamento intrapessoal, necessárias para a condução de trabalhos em equipes interdisciplinares. 


\section{Notas}

(1) Por ocasião de visita técnica da equipe (da qual eu era membro) que desenvolvia o programa municipal FavelaBairro a comunidade de Pavão-Pavãozinho - cidade do Rio de Janeiro -, acompanhado por representante das Nações Unidas, tiramos fotos a pedidos da criançada que nos rodeava. Uma das crianças, reconhecendo que usávamos máquinas digitais, pediu para que nós enviássemos as fotos para o seu e-mail. As crianças tinham acesso à internet na escola e numa ONG que trabalhava junto à comunidade.

(2) Ver BAKHTIN, Mikhail. Marxismo e filosofia da linguagem. São Paulo: Hucitec. 1997.

(3) Tomo emprestado do arquiteto e urbanista Ricardo Guerra Florez a dualidade, sempre presente em seus trabalhos, entre a existência de entidades reais e ideais para cada foco de estudo proposto.

(4) Ver LEFEBVRE, Henri. Lógica formal, lógica dialética. Rio de Janeiro: Civilização Brasileira, 1983.p. 120.

(5) Para essa pesquisa foram realizadas pesquisas diretas com docentes e indiretas através de documentos disponíveis, dentre os quais destacam-se os Anais do I e II ENEPEA- Encontro nacional de professores de paisagismo de escolas de arquitetura, realizados respectivamente no Rio de Janeiro, em 1994, e em São Paulo, em 1995.

\section{Bibliografia}

ANAIS DO I ENEPEA — Encontro Nacional de Ensino de Paisagismo em Escolas de Arquitetura. Rio de Janeiro, 1994.

ANAIS DO II ENEPEA — Encontro Nacional de Ensino de Paisagismo em Escolas de Arquitetura. São Paulo, 1995.

BAKHTIN, Mikhail. Marxismo e filosofia da linguagem. São Paulo: Hucitec, 1997.

BRASIL. Lei n. 9.394, de 20 de dezembro de 1996. Estabelece as diretrizes e bases da educação nacional. Disponível em: <http://www.mec.gov.br>, 2004.

Portaria n. 1.770 - MEC, de 21 de dezembro de 1994. Fixar as diretrizes curriculares e o conteúdo mínimo do curso de graduação em arquitetura e urbanismo. Disponível em: <http://www.asbea.org.br>, 2004.

Proposta de Diretrizes Curriculares Nacionais Para o Ensino de Graduação em Arquitetura e Urbanismo, tendo em vista o disposto no art. 9요 § 2, alínea ' $c$ ', da Lei n. 9.131, de 25 de novembro de 1995. Dispónível em: $<$ http://www.asbea.org.br>, 2004.

FREIRE, Paulo. Educação e mudança. Rio de Janeiro: Paz e Terra, 1979.

. Pedagogia do oprimido, Rio de Janeiro: Paz e Terra, 1987.

. Pedagogia da autonomia. 5 ed. São Paulo: Paz e Terra, 1996. (Coleção Leitura).

MAGNOLI, Miranda Martinelli. Conferência. In: II ENCONTRO DE ENSINO DE PAISAGISMO EM ESCOLAS DE ARQUITETURA E URBANISMO NO BRASIL. 1996, São Paulo. Anais... São Paulo: Unimarco, 1996.

Espaços livres e urbanização: Uma introdução ao aspecto da paisagem metropolitana. 1982. Tese (Livre-Docência) - Faculdade de Arquitetura e Urbanismo, Universidade de São Paulo, São Paulo, 1982.

MARICATO, Ermínia. Brasil, cidades: Alternativas para a crise urbana. Petrópolis: Vozes, 2001.

MORIN, Edgar. Os sete saberes necessários à educação do futuro. Brasília: Unesco, 2002.

SANTOS, Milton. O país distorcido. São Paulo: Publifolha, 2002.

Conferência. In: II ENCONTRO DE ENSINO DE PAISAGISMO EM ESCOLAS DE ARQUITETURA E URBANIS$\overline{\mathrm{MO} N O}$ BRASIL. 1996, São Paulo. Anais... São Paulo: Unimarco, 1996.

SCHÖN, Donald A. Educando o profissional reflexivo: Um novo design para o ensino e a aprendizagem. Porto Alegre: Artes Médicas Sul, 2000.

VYGOTSKY, L. S. Pensamento e linguagem. São Paulo: Martin Fontes, 1992. 
